Article

\title{
Exercise as Labour: Quantified Self and the Transformation of Exercise into Labour
}

\section{Chris Till}

School of Social, Psychological and Communication Sciences, Leeds Metropolitan University, Room 914, Calverley Building, Portland Way, Leeds, LS1 3HE, UK; E-Mail: c.till@leedsmet.ac.uk; Tel.: +44-0113-81-21886

Received: 17 March 2014; in revised form: 21 August 2014 / Accepted: 25 August 2014 /

Published: 28 August 2014

\begin{abstract}
The recent increase in the use of digital self-tracking devices has given rise to a range of relations to the self often discussed as quantified self (QS). In popular and academic discourse, this development has been discussed variously as a form of narcissistic self-involvement, an advanced expression of panoptical self-surveillance and a potential new dawn for e-health. This article proposes a previously un-theorised consequence of this large-scale observation and analysis of human behaviour; that exercise activity is in the process of being reconfigured as labour. QS will be briefly introduced, and reflected on, subsequently considering some of its key aspects in relation to how these have so far been interpreted and analysed in academic literature. Secondly, the analysis of scholars of "digital labour" and "immaterial labour" will be considered, which will be discussed in relation to what its analysis of the transformations of work in contemporary advanced capitalism can offer to an interpretation of the promotion and management of the self-tracking of exercise activities. Building on this analysis, it will be proposed that a thermodynamic model of the exploitation of potential energy underlies the interest that corporations have shown in self-tracking and that "gamification" and the promotion of an entrepreneurial selfhood is the ideological frame that informs the strategy through which labour value is extracted without payment. Finally, the potential theoretical and political consequences of these insights will be considered.
\end{abstract}

Keywords: digital health; digital technologies; health and illness; self-tracking; quantified self; labour 


\section{Introduction}

The recent increase in the use of digital self-tracking devices has given rise to a range of relations to the self often discussed as quantified self (QS). In popular and academic discourse, this development has been discussed variously as a form of narcissistic self-involvement, an advanced expression of panoptical self-surveillance and a potential new dawn for e-health. This article proposes a previously un-theorised consequence of this large-scale observation and analysis of human behaviour; that exercise activity is in the process of being reconfigured as labour. This is not, however, an ontological argument suggesting that exercise is inherently labour. Rather, it is proposed that in our present context, exercise and labour are in a process of merging in such a fashion that in a short space of time, the two may seem inseparable. This position was arrived at by thinking through the similarities between the activities undertaken by self-trackers and those discussed as "digital labour" [1]. A significant amount of the novelty of this position is derived from focusing the analysis on the strategies of the corporations who develop and control self-tracking devices rather than the users themselves. The main reason why it is proposed that digital tracking devices are having a considerable impact upon how exercise is understood is because of their ability to objectify and standardise the activities and capacities of heterogeneous bodies in such a fashion that value can be extracted.

This article will first introduce QS and consider some of its key aspects in relation to how these have so far been interpreted and analysed in academic literature. Secondly, the analysis of scholars of "digital labour" and "immaterial labour" will be considered in relation to what its analysis of the transformations of work in contemporary advanced capitalism can offer to an interpretation of the promotion and management of self-tracking of exercise activities. In the third section, the analysis will be built around two key analytical axes of a thermodynamic model of energy and that "gamification" and entrepreneurial selfhood are proposed as the ideological frame of commercial interest in self-tracking. Finally, the potential theoretical and political consequences of these insights will be considered.

\section{Quantified Self}

There has been a significant increase in the use, and particularly the sale, of devices or smart phone applications that enable the tracking and analysis of various aspects of everyday life. Most prominent amongst these are devices, such as the Nike+ Fuelband, FitBit and Jawbone Up; bracelets with built-in accelerometers that can track the distance the user has travelled, how many steps they have taken and other aspects of their activity. These activities are transformed into digital data, which are uploaded to servers owned by corporations, where they provide users with tools to analyse their progress and share their information with other users. In exchange for these services, the corporations collate data on their users, which can be used for various marketing and other purposes. A number of groups have developed around the use of such devices, most prominently a loose global network of quantified self "meetups" or "show and tells", during which users of devices or techniques present the novel ways they have developed to track, analyse and interpret their bodies, moods and other aspects of their lives.

These devices and their users are of increasing interest to academic researchers, and work has been conducted particularly in the field of human computer interaction [2], which has explored the 
potential of applications for tracking anxiety [3], sleep [4] and the relationship between health tracking and social networks [5]. The majority of the work has developed out of previous analyses of e-health and $m$-health predominantly in health promotion and health communication circles [6]. Some literature has focused on the potential for automisation, personalisation of information or prompts and the development of online support communities [7] (p. 330). A range of studies has explored the efficacy and potential of dietary and physical activity interventions through digital tools [8-12], and the wide-ranging implications of "Web 2.0" technologies have been surveyed [13]. Some ethnographic approaches to the use of information technologies in a healthcare setting have been attempted, in particular analysing the ways in which they are implicated in social practice [14], although this approach has not yet been taken to the more informal and commercial technologies and practices central to this study. Even studies focusing on "consumer e-health" have not so far dealt with the use of digital data and health data collection devices [15].

Although published work in the social sciences and humanities so far is limited, there have recently been a number of conference presentations that have often focused on surveillance [16], as well as notions of the "calculating self" [17] and the relationship between self-quantification and neo-liberal philosophies [18]. In the still relatively sparse published material, the theoretical implications of the use of such methods of digital self-analysis has been explored in relation to issues of surveillance and self-surveillance [19-21] and notions of "gamification" [22]. Perhaps the most well-developed published sociological work is that of Deborah Lupton, who has suggested that self-tracking and QS can be read in terms of:

- A "body-machine" metaphor with the body defined in terms of quantified "inputs" and "outputs" with self-trackers positioned as "experimenters" on their own bodies [23] (pp. 26-27).

- An expression of neo-liberal entrepreneurialism, enabling self-maximisation and promoting self-critique and responsibilisation through the presentation of "objective" measures of performance [23] (p. 28).

- Practices of "prosumption" characteristic of the use of Web 2.0 in which users are both consumers and producers of digital media content, which is the context for the constitution of virtual and physical communities [23] (pp. 28-29).

- A means through which a particular kind of reflexive approach to the self is enabled through the analysis of data and the imperative to control these data and oneself [23] (p. 29).

While I agree there is a lot of potential in interpreting self-tracking activities along the above axes, and I would consider this article to complement these approaches, there is an important aspect of such practices that has yet to be theorised. This supplement to the above analyses was arrived at largely through an engagement with the literature on digital labour.

\section{Digital Labour}

While all of the devices that are used for exercise and health tracking, and some of the apps, generate income through sales for the corporations who provide them, it is clear that the data that are produced are also valuable. Some prominent figures in QS have been calling for the companies who produce the devices and apps to allow the users greater ownership over their data [24-26]. Currently, 
the data generated through tracking are tied up within corporate walls, making it difficult for individual users to merge data from different devices in order to gain a more holistic picture of their health. Nike, Jawbone and the other corporations have so far not been enthusiastic about doing this. In recent years, the value of user data to corporations has become clear. While it is not yet fully known how corporations are using these data, Nike and Fitbit have both stated that while they do not sell personally identifiable information, they may do so with aggregate data or share with others within their "corporate umbrella" [27].

While this kind of sharing could effectively function as the de facto sale of commercial data, clearer sharing between companies has recently been unearthed. A study of twelve mobile health and fitness apps conducted by the U.S. Federal Trade Commission found that user data were disseminated to seventy-six third parties, and one app in particular sent data to eighteen other entities [28]. In addition to information, such as names, email addresses and usernames, twenty-two of those third parties received details on consumers, such as exercise information, meal and diet information, gender and geo-location [29]. A similar study by web analytics and privacy group Evidon commissioned by the Financial Times found that the twenty most popular health and fitness apps share information with almost seventy companies. In particular, MapMyRun was found to transmit data to eleven companies, some of which were advertising firms [30].

Another route by which these data may be shared is through corporate takeovers. When fitness tracking app Moves was purchased by Facebook in April, 2014, they announced that their data would not be "commingled" with one another. Within two weeks of the purchase, they changed their terms of service and privacy policy to state that they will share data with Facebook and their other affiliates [31]. Perhaps most telling, an analysis of the privacy policies [32] (pp. 73-78) of many of the most popular health and fitness tracking apps and devices found that most were ambiguous on whether they permitted sharing of user data, with most allowing "non-personally identifiable information" to be passed on. Such aggregated data would be of great value for advertising. Corporations have not divulged for what purposes these data are being used, but we already know that the billions of dollars that companies, such as Facebook and Google, have made over the last decade have been generated largely from selling advertising space on the basis of data collected on their users. The character of Web 2.0 media is such that users are usually both the audience for, and producers of, media content and so are therefore targets of advertising and responsible for drawing in an audience who is exposed to advertising.

A significant literature has developed trying to understand the implications of the use of this "digital labour" or what Tiziana Terranova [33] called "free labour". Terranova has suggested that the kinds of activities conducted online are symptomatic of "an acceleration of the capitalist logic of production" [33] (p. 46). The profitability of sites, such as Facebook, is dependent upon the users and "the cumulative hours of accessing the site (thus generating advertising), writing messages, participating in conversations and sometimes making the jump to collaborators" [33] (p. 48). This "free labour" generates vast amounts of income, but is not paid, because the corporations have successfully convinced users that it is leisure, not labour, through an erosion of the distinction between work and play [1] (p. 2) and the formation of what some have called "playbour" [34]. The clicks, "likes", purchases and posts performed by users as part of their everyday usage of the Internet provide valuable data, which can then be sold on to advertisers. 
Critiques of digital "free labour" have been significantly influenced by autonomist Marxist and Operaismo work on the "social factory" [35] and "immaterial labour", which tried to deal with the consequences of the decline in traditional forms of productive labour in Western countries and the rise in knowledge economies. As described by the autonomists, the context in which "cognitive labour" has increased in prominence can be characterised by the emergence of increasingly precarious forms of intellectual and affective labour. The rise of this kind of labour has seen the dismantling of the structured, bounded, restricted, waged workday governed by rules, obligations and expectations [36] (p. 26). The twentieth century, "modern" form of work organisation is being replaced by decentralised, temporary employment in which work is often intricately intermingled with creativity and self-realisation, making it increasingly difficult to differentiate between work, leisure and individual life projects and easier for corporations to benefit from "free labour". The analysis of "digital labour" and that of the autonomist Marxists is predicated on the assumption that labour is not only that which is paid formally through wages. Rather, many forms of activity generate value, and there are forces at work that coerce people into accepting the necessity of engaging in such productive activities for little or no pay.

The theoretical approach taken in this article has some affinity with that in studies of the "commercialization of leisure time", which highlights not only that that the line between work and leisure is increasingly blurred, but that the notion of leisure time itself is at least partly a product of the capitalist organisation of work [37]. Capitalism has reformulated people, not only as workers, but as consumers who decreasingly have the means to engage in leisure activity without consumption. Thus, the commodification of leisure time is seen as being intimately linked with proletarianization and the extraction of surplus value [38] (p. 218). Moreover, the activities of leisure come to increasingly resemble those associated with work; this fusion of "working time" with "leisure time", both for worker and capitalist, is aided by the kind of work associated with "immaterial labour" [39] (p. 98). The contemporary orientation of capitalism towards the extensive appropriation of subjectivity and social relations that is captured in the notion of immaterial labour [40] finds particularly fertile ground in the digital world [41].

The fundamental aspect that is of significance for this article is the creative and open view of what can be defined as labour in the above analyses. In one sense, digital labour can be seen merely as a particularly advanced form of the division of labour dominant in the twentieth century, with the individual tasks of writing posts and liking photographs distributed between many different people. This is, however, quite different from a traditional factory production process in which the product is designed as an end-point and the production process broken down into individual elements that are distributed among many hands, because the product of most digital labour is data on its own producers. Even the most complex and advanced products of conventional labour are not as inherently tied to their distributed production process as the data generated through digital labour. In very few circumstances could the product of digital labour exist as a valuable commodity outside of the processes of its own collective production. The production of digital labour is its product. Before applying this analysis to digital self-tracking of exercise, it must be established precisely what is meant by labour in this case. 
In the following section, I will describe how a similar process of the accumulation of labour in order to enable its standardization and quantification is being applied to exercise activity through the use of digital self-tracking devices.

\section{Self-Tracking}

With the use of digital self-tracking devices, we are currently witnessing the transformation of individual health activities into quantified forms ripe for the extraction of value with a variety of health apps and tracking devices. We can easily see exercise in any form as a type of "formative activity", which, as Sayers [42] (p. 435) states, could be to "change the character of animals or people" as much as to give form to raw materials. It is clear that people see their achievements in exercise (whether in the form of medals or rankings in professional or amateur sport, lifting particular weights or running certain distances) as a certain kind of objectification of their labour, which they recognize as embodiments of their abilities. While exercise may not always be productive of economic value, it certainly often produces objectified embodiments of the labour exerted and entails shaping and changing the character and body of a person, usually one's self. While there are many kinds of satisfaction that can be derived from exercise, certainly a major one would seem to be the objectified measures of achievements. A central aspect of the success of self-tracking devices and related analytical software has been virtual versions of such measures of achievement. Many applications offer "badges" or "medals" for achieving goals, with some, such as Strava, encouraging competition by awarding titles, such as "King of the Mountain", for the quickest time cycling up a particular hill [43]. The satisfaction gained by some in attaining such achievements is clear, and the use of such methods has been called "gamification", to which I will return below.

The quantification of particular exercise activities for individuals, then, has benefits that are largely consistent with older analogue forms of self-tracking and quantification, such as measuring distance run on a map, counting and logging the amount of press-ups performed or the logging of scores and positions in a squash or football league $[18,44]$. Digital self-tracking systems automate many of these processes, enable more minute measurement (in some cases) and, in particular, enable a greater amount of people against whom performance can be compared. The benefits to corporations are, however, of a completely different order: the commodification of exercise activity. Previously, the commodification of exercise activities had always taken a largely indirect approach. To take running as an example, capitalist enterprises have made money from running as an activity through the marketing of products, such as running shoes or t-shirts, which are purported to improve performance or make the activity more comfortable.

Through the large-scale quantification of running enabled by digital tracking devices, however, the activity itself is being turned into a form that is amenable to the extraction of value. In the past, the actual activity of running was only of value to the individuals themselves, and this could only indirectly result in economic value, except for professional athletes. When exercise activities are quantified in a standardized form that is amenable to comparison and accumulation, corporations can use the associated data in order to extract surplus value. Just as the clicks performed by individual Facebook users contribute towards the production of useful data for advertisers, so do the exercise activities performed by users of Fitbit or Track My Run. We can, then, see the quantification of 
exercise activities through digital self-tracking as a method of enabling the "accumulation of labour" in order to prepare it for the extraction of surplus value. Users of such devices have thus been convinced to pay for the chance to give away their productive labour to corporations who will use it to generate customer profiles to be sold to advertisers who will then target the users with more products.

What are the consequences of a theoretical approach that conceptualizes the labour of self-trackers or self-quantifiers as labour? To my mind, this kind of analysis is necessary regardless of how we might like to conceptualise exercise activities that are tracked; they are labour, because the corporations are treating them as such. Surplus value will be extracted from these activities by corporations, as if they were work; if we do not recognise it, then we cannot challenge it. To approach digital self-tracking of exercise activity as a form of labour, therefore, is to "follow the medium" [45] (pp. 26-27). This may potentially lead to a reformulation after which (at least, for some people) exercise activity is deemed to be more worthwhile if it is being tracked, accumulated on a server and mingled with the data of other users. Furthermore, there may be further consequences (which will be explored below) with regards to what constitutes labour. Literature addressing the commercialization of leisure time [37-40] has suggested that the boundaries between labour and non-labour have been blurred; this has intensified with the commercialization of self-tracking data.

If the position presented in this paper is acknowledged, then there may be a situation of perpetual commercial reinforcement between work, exercise and advertising. The focus on productivity in self-tracking draws it conceptually closer to commercial imperatives than other forms of commercialization of leisure time, even when commerce is not directly involved. We can see this in the ways in which personal tracking and employer monitoring are converging, as exercise tracking apps are always in some sense productivity monitors. Moreover, digital and mobile productivity apps, such as DeskTime, are also increasingly being used by employers to monitor, and employees to prove, productivity. One app, iDoneThis, started as a "personal productivity tracker for weight reduction" and is now used as a subscription service business management tool. As Phoebe Moore [46] has shown, such techniques and technologies are being used by a variety of large and diverse organisations, such as Tesco, Amazon and the Defense Advanced Research Projects Agency, to track the productivity and health behaviour of employees in order to intervene and improve both. These initiatives are, however, not simply panoptic, authoritarian surveillance by employers. Rather, they are couched in terms of a mutually beneficial situation that improves the health and wellbeing of employees, as well as increasing productivity and lowering costs for employers [47,48]. While these "corporate wellness" strategies emphasise that employers must take action, this tends to be in the form of enabling and encouraging "complete lifestyle and behaviour change" [49] in employees.

Those concerned with employee health have discovered useful tools in digital tracking technologies with "employee wellness programs" being reported to be one of Fitbit's fastest growing areas of expansion [50]. The data produced by devices, such as Fitbit, are conducive to existing techniques of corporate management in which workers are managed in terms of their quantified measures of productivity. A corporate wellness program implemented by BP America, which distributed free Fitbit devices to employees, spouses and retirees, helped to reduce their healthcare costs to below average growth rates in the U.S. [51]. In these cases, any line between what is beneficial for the profitability of the company and the health and wellbeing of the employee is thoroughly blurred, and as the health 
data generated on employees become more comprehensive and thoroughly integrated into the financial concerns of the company, the distinction will become even hazier.

This is, then, perhaps best characterised as "syndromic surveillance", or the real-time monitoring of patterns through "automated data acquisition" [52], which has brought together health and commercial data in new ways. Public Health England conducted research [53] that drew on supermarket purchase data largely from loyalty cards to identify the supermarkets that had the highest levels of purchases of "unhealthy". Their analysis was used to target interventions to reduce obesity. It has also been reported [54] that data brokers are selling consumer data on transactions to healthcare providers, which is being used to create profiles on current and potential patients. These data may include purchases of food and cigarettes, as well as gym memberships. The distinction between health and commercial data is becoming unclear, and the techniques of profiling and prediction used by marketers, healthcare providers and public health are converging. A potential outcome of this could be that our health, and potential future health, will increasingly become defined in relation to complex data that we generate in a variety of different contexts.

As I see it, this article complements and adapts the four key aspects (outlined above) of Lupton's analysis of self-tracking: that there is a "body-machine metaphor" at work; it is an expression of "neo-liberal entrepreneurialism"; it is characteristic of "prosumption" practices; and it is an enabler of a particular approach to self-reflexivity [23] (pp. 26-29). By approaching the exercise activities associated with self-tracking as a form of labour, these four analytical axes are modified slightly. It is on the first two ("body-machine metaphor" and "neo-liberal entrepreneurialism") that I will concentrate, however, as these are the most significant to this analysis.

\section{Thermodynamics and "Gamification"}

The body machine metaphor suggested by Lupton [23] (pp. 26-27) is certainly present in descriptions of QS in the media and other representations, and this may well be how many users perceive their relationship towards themselves as mediated through their devices. Lupton's use of this metaphor is informed by Donna Haraway's [55] theorisation of the "cyborg", which she used to capture the contemporary assemblages of humans and technologies. The integration that wearable devices have with the body enables the cyborg to develop ever further and to constitute new relations with the body and others. It is, however, the notion of the body as a series of codes, which Haraway proposed in relation to discourses of disease, which is particularly enlightening here. As Lupton [56] demonstrates, data produced through self-tracking appears to render the messy, disordered body as clean and orderly and give us the tools to maintain control through an objective view of the body.

While the body is often conceived of in terms of inputs and outputs of energy by individuals, the corporations, by constituting users as workers in a distributed digital exercise factory, are working on a different model. Rather than the individual exerciser being considered as an isolated, molar individual, they are seen as an expression of universal energy, as a generator of data. In order to understand this, we need to think in terms of a thermodynamic metaphor based on energy and what methods of analysis have enabled this model. According to the thermodynamic model, the universe contains a fixed amount of energy that can neither be created nor destroyed, only harnessed or not. For George Caffentzis [57], energy became central to the management of work from the nineteenth century 
onwards. In early capitalism, the key tension between capitalists and labour was hours worked; in the nineteenth century, this shifted to an issue of "productive intensity", or, how to transform the workers' energy into work. This was seen to be fundamentally similar to the notion in theories of thermodynamics that "if a mass is exploding, you should give it a way out so organized that it will push a piston and thus do work for you" [57] (unpaged). In order to harness this energy, there needed to be a form of analysis; it needed to be "caught, fixed, and serialized" [58] (p. 39) and could, therefore, be quantified. By making physical work able to be perceived as a series of isolated movements, this new approach presented the human body as a "thermodynamic machine" [59] (p. 30) with "work" (in terms of labour and physics) seen as a manifestation of the "energy" that underlies all of nature. The exercise in which many people engage for fitness purposes has (in capitalist terms) been wasted for decades. Digital self-tracking is an ingenious means by which energy that is being expended anyway can be analysed and transformed into productive, profitable (unpaid) "work".

This analysis develops the body-machine metaphor that has previously been applied to self-tracking by taking the analysis below the level of the individual body to think in terms of the energy used by collections of bodies. Thinking of the body in terms of energy or data performs similar functions as it reduces particular bodies, or actions, down to a common, universal, abstract quantifiable substance. It is possible to understand the actions of those engaged with exercise data, whether individuals, governments or corporations, in terms of the harnessing of potential energy, which requires knowledge of the energy expenditure of the individual. Furthermore, this has the impact of aggregating a population in terms of their energy. Quantifiable measures, such as those generated through self-tracking, provide the potential to compare and accumulate individuals into a generalized mass.

In order to make this labour productive, however, the corporations cannot stop at the point of merely tracking existing exercise, but must encourage exercise and structure it in such a fashion that it is useful for their purposes. The virtual achievements associated with "gamification" may be determined by what the corporations think customers want (supply and demand), but are also driven by what kinds of data they want to generate and, therefore, the kinds of labour in which they want users to engage. "Gamification" here helps to explain not only how people are drawn into engagement with systems of production, but how their "work" is managed in a decentralized, distributed "factory". If we consider the issue of "gamification", not in terms of the pleasures enabled (although these are significant), but in terms of the productive labour generated, then we see that '[i]t isn't play that creates its own games; it is a game that extracts labour in the form of play" [60] (p. 74). This "gamification" can, then, be seen as encouraging a kind of neo-liberal entrepreneurial self, which is "amenable to improvement, an object of personal enterprise and work" [23] (p. 28).

We can further see the relation between exercise and labour as the kinds of "gamification" employed in self-tracking converging with that used in management practices. Some have suggested that gamification could be almost a panacea for the problems faced in the contemporary workplace, tackling stress, reduced sense of community, reduced loyalty and a rapidly changing workforce [61]. A senior Microsoft director has proclaimed that "play is the future of work" [62], and gamification will enable work to become a freeing and creative process. The rhetoric of these approaches is one similar to a gift economy, where employees giving a little extra in their daily work in return for the pleasure they gain from the experience of the game. For McKenzie Wark, however, this is a distinctly imbalanced 
exchange, where "what is offered is a bit of cognitive energy that performs a task some vectoral business requires, and the reward is only a formal and abstract kind of token and ranking" [60] (p. 74).

When the activities that are being "gamified" produce commercially useful data, this can be seen as a form of division of labour, which is most widely seen through "crowdsourcing", in which a task is divided between a vast number of people in order to gain a quick or cheap result. While this kind of labour organisation has often been traded on the goodwill and enthusiasm of the public for scientific experiments and other "worthy causes", when harnessed for commercial purposes, it can be seen as a type of "labour arbitrage" [63], a "neoliberal system of exception" [64] (p. 91) or simply work that does not need to be paid. To highlight that these data are or can be valuable to corporations does not deny its usefulness to users just as the "critique of exploitation does not devalue individual pleasure any more than such pleasures nullify exploitative social relations" [65] (p.153). Furthermore, self-tracking devices have been shown to tend towards individualization and the solidification of existing economic and political divides [66] (p. 81).

We can, therefore, see the thermodynamic harnessing of potential energy latent in the population as the labour model underlying the commercial interest in tracking exercising bodies and "gamification" and the promotion of an entrepreneurial self as the strategies through which labour value is extracted with minimal payment. It now leaves us to consider what the potential theoretical and political consequences of these insights might be.

\section{Consequences}

Some might accept the conceptualisation of exercise activities as a form of productive labour, but be less willing to deem it a significant problem, given that it is generally engaged in freely; the users enjoy and benefit from it, and users tend to be relatively prosperous, unlike some others who experience more severe extraction of their "free labour" (see, for instance, Amazon's "Mechanical Turk" [64]). The success with which corporations have been able to convince people to reconstitute their exercise activities into productive labour and to give it away freely may encourage them to expand this project in as yet unimagined ways. Indeed, there have already been proposals to use digital self-tracking devices in order to monitor traditional workplace activities [67]. Furthermore, while the kind of exploitation of labour that is occurring in this case may not be of the most serious kind, there are structural and analytic similarities with the highly exploitative kind of labour relations, which should be highlighted [67] (p. 155). If it is agreed that these labour practices are problematic, then they would need to be tackled multilaterally. The commercialisation of exercising bodies in the form we have been discussing could have potential ramifications for how such activities are conceptualised in the long term. While I have focused on exercise in this article, it is true that any tracked movement could be considered as productive of valuable data. I have concentrated on exercise because corporations are demonstrably interested in the tracking of exercise data, which also has clear commercial value. Moreover, there are potentially specific conceptual consequences to the tracking of exercise, since, just as the constitution of a "like economy" or "click economy", in which value can be extracted from users' everyday interactions on the Internet required a process of enclosure, so is this occurring in the present case. 
The early Internet was often spoken about in utopian terms as a free "commons"; this has now been extensively "enclosed" and turned into a private space kept within the walls of Facebook or Google. Today, the vast majority of people engaged with the Internet have many of their social interactions mediated through commercial, enclosed spaces managed by corporations. Such corporations are only able to appropriate value through "capturing and controlling components of the productive infrastructure" [65] (p. 155) of the Internet. If a similar process of enclosure is occurring through digital self-tracking devices, the "productive infrastructure" that is being captured and controlled is, at least in part, the productive bodies of the population. These are forms of exercise that were previously undertaken, usually for reasons of health, socialization or personal development. Commercialization could have a significant impact on how such activities are perceived and experienced. Early and enthusiastic adopters of digital self-tracking already report a disengagement from exercise that is not being tracked.

The analysis in this article could make a contribution towards the ongoing theorisation of "immaterial labour" by problematizing the distinction between material and immaterial as self-tracking highlights that all of the work undertaken as "digital labour" is corporeal on some level. While "cognitive labour" has been considered to be particularly amenable to the kinds of "labour arbitrage" [64] (p. 91), which exploits "immaterial labour" through creating a "system of exception" in which particular activities are deemed unworthy of payment, the present case shows that there is nothing to stop "material labour" from being organised along similar lines. This insight perhaps points to the material aspect of all "immaterial labour", even if, in some cases, this appears to be merely the pressing of keys or clicks of a mouse. We might, therefore, consider to what extent digital self-tracking has the potential to contribute towards resistance to capitalist appropriation. The transformation of exercise activity into a quantified form has similarities with traditional forms of labour organization in the sense that it provides a way to realize our collectivity. The value that corporations extract from exercise collectively enables users to see their exercise activities as something more than merely individual activity. Just as the "collective knowledge work" that occurs in the digital economy demonstrates the "collective aspect of labour [which] implies a rejection of the equivalence between labour and employment... [and shows that]...[1] abor is not equivalent to waged labour" [33] (p. 45), so could "collective exercise work". The labour engaged in by self-trackers is both "knowledge work" and "physical work", "immaterial labour" and "material labour", if indeed we require distinctions between the two.

Those engaged in the QS community are much closer to this kind of resistance than the more casual self-trackers who use "off the shelf" devices or applications. While part of this more creative approach to self-tracking is due to the "hobby-ist" and "techie" tendencies of many people involved in QS, it is also in response to issues around the management of data. While much of the academic literature assumes that the biggest issues for those in the QS community are around surveillance and self-constitution, some of the more vocal members seem to be equally interested in the control of data. In particular, some have attempted to find ways to enable users to manage their data online through open-source software [25]. There have also been particular critiques [26] of how the infrastructure of self-tracking devices and services works. Currently, individuals have little ownership over their data, because the companies that produce each device they use want to tie users into their "ecosystems" of online analytics services and social networks. It has been proposed [26] that they should hand the data 
over to the users, making it easier for them to control how their data are used and who has access to it and making it more feasible to combine data streams from different devices.

The developments discussed in this article, therefore, suggest a problematisation of the immaterial/material distinction and of what constitutes work labour. The critique offered by operaists demonstrates that the boundary between work and leisure has been collapsed and has sought to demonstrate that the activities they classify as immaterial labour are indeed labour, but a different form to traditional material labour. Their focus, however, was on the products of the labour process, in which case, approaching the two kinds of activities as distinct makes sense. Material labour produces material goods, while immaterial labour produces immaterial goods. If we focus on the process of production, however, this distinction seems less meaningful, as material and immaterial goods both require physical activity of some kind, whether this is the pressing of keys or firing of neurons. Similarly, if indeed exercise activity can be considered to be labour that produces material goods (in the form of the transformation of human bodies) and immaterial goods (in the form of data), is this distinction between material and immaterial still meaningful?

We might also consider the potential impact of this analysis on the ways in which health in general is conceptualised. If digitally tracked and quantified exercise activity can be formulated in terms of labour, does this mean that all exercise activity should be? In the case of self-tracking, it is politically important to consider this reconceptualization, because exercise activity is being structured in such a fashion as to have economic value extracted from it. While the activity of exercise has always been able to produce certain use values (e.g., improved health, development of skills), it is only because it is being tracked and accumulated along with the data of others that it is able to produce exchange value in the form of commercially valuable data. As studies have shown [30,32], data from health and exercise apps are being shared not only between entities under the same "corporate umbrella", but with external companies. It is important to remember that it is the standardization through quantification in the process of digital tracking that enables exercise activity in this case to be formulated as a collective, distributed form of labour. This is not usually the case in everyday, untracked exercise activity, and it is probably not desirable to consider it in these terms. Significantly, the value that is produced through tracking is likely to be derived from its value in generating promotional data, and it is perhaps for this purpose that exercise activities are tracked, quantified, accumulated and analysed. Nevertheless, if the tracking, quantification, accumulation and extraction of value from exercise activity continues to grow, it is possible that the definition of what constitutes worthwhile exercise may become increasingly aligned with commercial imperatives.

As an increasing amount of exercise activity is tracked, accumulated and analysed, a conceptual distinction may develop between those activities that are and are not capable of being quantified. Might we come to distinguish between exercise that is productive and unproductive of data? This could speak of a new kind of commercialization of exercise that is much more pervasive than the production and promotion of sports equipment, for instance, but brings the bodies and movement of amateur athletes itself into the commercial infrastructure. If the actual movements of the exercising body are generating valuable data, this might change the ways in which people (as well as corporations) engage with exercising bodies. There could be a developing expectation that we will be producing valuable data when at work, when exercising and when at rest. 


\section{Conclusions}

The few sociological approaches to digital self-tracking have tended to focus on surveillance or the micro-level impact on individuals and their relationship to the self. These have been valuable and look likely to inspire useful empirical work; however, a focus on the macro level tactics of the corporations who are largely in control of the data provides different insights. By considering self-tracked exercise activity in terms of its corporate value, we can see how it is digitized, quantified, accumulated and analysed in order to generate commercially valuable data on the population. These data are particularly valuable to the corporations who are collecting it, because it has been ideologically constituted as "not work" and, therefore, not being worthy of payment. It has been suggested above that there are "structural similarities" between the "digital labour" or "free labour" that is conducted online and the digitally-tracked exercise activities of users of self-tracking devices. When approached through a Marxist frame of analysis, it is possible to see the digital tracking of exercise activities as a form of the accumulation of labour, which enables the extraction of surplus value. The transformation of exercise activities into digital data enables individual users to see their activities as a particular kind of "formative activity" through the representation of their achievements as digital data in the form of statistics or "medals", which constitute a kind of objectification of the labour of the exerciser, which is relatively new to the amateur athlete. For corporations who are compiling these data, however, by transforming heterogeneous exercise activities into a standardized, quantified form, they are able to be made into a valuable resource; data that can be sold to advertisers. The exercise activities in which people engage are therefore seen as productive potential energy by corporations, who are likely to be using the design of hardware and software to subtly structure the behaviour of users to produce the kinds of data that will be of commercial value. Prior to the existence of easily available digital tracking technologies, there were few ways in which everyday exercise activities could be quantified and standardized in such a form that they are amenable to the accumulation and comparison of the data of large amounts of people. These developments are currently in their early stages, but may be indicative of not only a new form of surveillance, but an epistemological change in how exercise is understood, as well as signaling the potential commercialization of the exercising bodies of the population.

\section{Acknowledgments}

I am grateful to Karen Throsby, whose comments helped me to improve this article considerably, but any mistakes or deficiencies are entirely my own. I am also indebted to the anonymous reviewers of this paper, whose constructive criticisms improved it immeasurably.

\section{Conflicts of Interest}

The author declares no conflict of interest.

\section{References and Notes}

1. Scholz, T. Why Does Digital Labor Matter Now? In Digital Labor: The Internet as Playground and Factory; Scholz, T., Ed.; Routledge: London, UK, 2013; pp. 1-9. 
2. Li, I.D.; Dey, A.; Forlizzi, J. A Stage-Based Model of Personal Informatics Systems. In CHI (Computer-human Interaction) 2010, Proceedings of the SIGCHI Conference on Human Factors in Computing Systems, Atlanta, GA, USA, 10-15 April 2010.

3. Alabi, H.; Gooch, B. Mobile Device Application of Cognitive Behavioral Therapy Techniques. In CHI (Computer-human Interaction) 2011, Proceedings of the SIGCHI Conference on Human Factors in Computing Systems, Vancouver, BC, Canada, 7-12 May 2011.

4. Kay, M.; Choe, E.; Shepherd, J.; Greenstein, B.; Consolvo, S.; Kelley, P.G.; Kientz, J. Lullaby: Environmental Sensing For Sleep Self-Improvement. In CHI (Computer-human Interaction) 2011, Proceedings of the SIGCHI Conference on Human Factors in Computing Systems, Vancouver, BC, Canada, 7-12 May 2011.

5. Kamal, N.; Fels, S.; Blackstock, M. Personal Health Informatics: What is the role for online social networks? In CHI (Computer-human Interaction) 2011, Proceedings of the SIGCHI Conference on Human Factors in Computing Systems, Vancouver, BC, Canada, 7-12 May 2011.

6. Laakso, E.-L.; Armstrong, K.; User, W. Cyber-management of people with chronic disease: A potential solution to eHealth challenges. Health Educ. J. 2011, 5, 1-8.

7. Kreps, G.L.; Neuhauser, L. New directions in eHealth communication: Opportunities and challenges. Patient Educ. Couns. 2010, 78, 329-336.

8. Breton, E.R.; Fuemmeler, B.F.; Abroms, L.C. Weight loss - there is an app for that! But does it adhere to evidence-informed practices? Transl. Behav. Med. 2011, 1, 523-529.

9. Kroeze, W.; Werkman, A.; Brug, J. A systematic review of randomized trials and on the effectiveness of computer-tailored education on physical activity and dietary behaviors. Ann. Behav. Med. 2006, 31, 205-223.

10. Neville, L.M.; O’Hara, B.; Milat, A.J. Computer-tailored dietary behaviour change interventions: A systematic review. Health Educ. Res. 2009, 24, 699-720.

11. Vandelanotte, C.; Spathonis, K.M.; Eakin, E.G.; Owen, N. Website-delivered physical activity interventions: A review of the literature. Am. J. Prev. Med. 2007, 33, 54-64.

12. Van den Berg, M.H.; Schoones, J.W.; Vliet Vlieland, T.P.M. Internet-based physical activity interventions: A systematic review of the literature. J. Med. Internet Res. 2007, 9, e26.

13. Kamel Boulos, M.N.; Wheeler, S. The emerging Web 2.0 social software: an enabling suite of sociable technologies in health and health care education. Health Info. Libr. J. 2007, 24, 2-23.

14. Greenhalgh, T.; Swinglehurst, D. Studying technology use as social practice: The untapped potential of ethnography. BMC Med. 2011, 9, 45-51.

15. Horden, A.; Georgiou, A.; Whetton, S.; Prgomet, M. Consumer eHealth-an overview of the research and evidence and the implications for future policy. Health. Inf. Manag. J. 2011, 40, 6-14.

16. Albrechtslund, A. Self-surveillance: How Quantification Practices and Monitoring Technologies Produce Subjectivity. In Annual Meeting of the Society for Social Studies of Science (4S), San Diego, CA, USA, 9-12 October 2013; Unpublished conference paper.

17. Irwin, S. More than Gear and Gadgets: Self-Tracking for Elite Amateur Triathletes. In Annual Meeting of the Society for Social Studies of Science (4S), San Diego, CA, USA, 9-12 October 2013; Unpublished conference paper. 
18. Ruckenstein, M. Personal Analytics: The Politics and Temporalities of Self-tracking. In Annual Meeting of the Society for Social Studies of Science (4S), San Diego, CA, USA, 9-12 October 2013; Unpublished conference paper.

19. Bossewitch, J.; Sinnreich, A. The end of forgetting: Strategic agency beyond the panopticon. New Media Soc. 2013, 15, 224-242.

20. Lupton, D. The digitally engaged patient: Self-monitoring and self-care in the digital health era. Soc. Theory Health 2012, 11, 256-270.

21. Lupton, D. M-health and health promotion: The digital cyborg and surveillance society. Soc. Theory Health 2012, 10, 229-244.

22. Whitson, J.R. Gaming the Quantified Self. Surveill. Soc. 2013, 11, 163-176.

23. Lupton, D. Understanding the Human Machine. IEEE Technnol. Soc. Mag. 2013, 32, 25-30.

24. Bland, J. Big data gets physical. The Guardian, 27 January 2014. Available online: http://www.theguardian.com/science/political-science/2014/jan/27/science-policy?CMP=twt_fd (accessed on 27 January 2014).

25. Lukas, A. London QS Show \& Tell \#1 ñ Recap. Available online: http:/quantifiedself.com/2010/ 09/london-qs-show-tell1-recap/ (accessed on 29 January 2014).

26. Parecki, A. The Future of Quantified Self Devices. Available online: http://aaronparecki.com/ articles/2013/10/11/1/the-future-of-quantified-self-devices (accessed on 29 January 2014).

27. Liebelson, D. Are Fitbit, Nike, and Garmin Planning to Sell Your Personal Fitness Data? MotherJones, 31 January 2014. Available online: http://www.motherjones.com/politics/2014/01/ are-fitbit-nike-and-garmin-selling-your-personal-fitness-data (accessed on 28 February 2014).

28. Kaye, K. FTC: Fitness Apps Can Help You Shed Calories - and Privacy. Available online: http://adage.com/article/privacy-and-regulation/ftc-signals-focus-health-fitness-data-privacy/293080/ (accessed on 5 June 2014).

29. Federal Trade Commission. Internet of Things-Privacy and Security in a Connected World. Available online: http://www.ftc.gov/news-events/events-calendar/2013/11/internet-thingsprivacy-security-connected-world (accessed on 5 June 2014).

30. Steel, E.; Dembosky, A. Health apps run into privacy snags. Available online: http://www.ft.com/cms/s/0/b709cf4a-12dd-11e3-a05e-00144feabdc0.html?ftcamp=published_ links/rss/companies_media/feed//product\&siteedition=uk\&siteedition=uk\#axzz2do7q8k35 (accessed on 5 June 2014).

31. Pelegrin, W. After only 11 days, 'Moves' abandons promise, starts sharing all data with Facebook. Available online: http://www.digitaltrends.com/mobile/moves-app-shares-user-data-facebook/\#! SUZvF_(accessed on 5 June 2014).

32. Peppet, S.R. Regulating the Internet of Things: First Steps Towards Managing Discrimination, Privacy, Security \& Consent. Available online: http://papers.ssrn.com/sol3/papers.cfm?abstract_id $=2409074$ (accessed on 5 June 2014).

33. Terranova, T. Free Labor. In Digital Labor: The Internet as Playground and Factory; Scholz, T., Ed.; Routledge: London, UK, 2013; pp. 33-57.

34. Beer, D.; Burrows, R. Popular Culture, Digital Archives and the New Social Life of Data. Theor. Cult. Soc. 2013, 30, 47-71. 
35. Tronti, M. Factory and Society, Operaismo in English. Available online: http://operaismoin english.wordpress.com/2013/06/13/factory-and-society/ (accessed on 9 March 2014).

36. Ross, A. In Search of the Lost Paycheck. In Digital Labor: The Internet as Playground and Factory; Scholz, T.; Ed.; Routledge: London, UK, 2013; pp. 13-32.

37. Sotamaa, O. On modder labour, commodification of play, and mod competitions. First Monday 2007, 12, No. 9.

38. Butsch, R. The commodification of leisure: The case of the model airplane hobby industry. Qual. Sociol. 1984, 7, 217-235.

39. Coté, M.; Pybus, J. Learning to Immaterial Labour 2.0: MySpace and Social Networks. Ephemera 2007, 7, 88-106.

40. Brouillette, S. Creative Labor. Mediations 2009, 24, 140-149.

41. Cohen, N.S. The Valorization of Surveillance: Towards a Political Economy of Facebook. Democratic Communiqué 2008, 22, 5-22.

42. Sayers, S. The Concept of Labor: Marx and His Critics. Sci. Soc. 2007, 71, 431-454.

43. Barratt, P. Racing Strangers: The rise of the quantitative self application and the changing (virtual) landscapes and practices of cycling. In Proceedings of Quantified Self Research Network Seminar, Leeds, UK, 19 September 2013; Unpublished conference work.

44. Shove, E.; Pantzar, M.; Watson, M. The Dynamics of Social Practice: Everyday Life and How it Changes; Sage: London, UK, 2012.

45. Rogers, R. Digital Methods; The MIT Press: London, UK, 2013.

46. Moore, P.V. Tracking Bodies, the Quantified Self and the Corporeal Turn. In The International Political Economy of Production; Van der Pijl, K., Ed.; Edward Elgar: Cheltenham, UK, 2014, in press.

47. Mujtaba, B.G.; Cavico, F.J. Corporate Wellness Programs: Implementation Challenges in the Modern American Workplace. Int. J. Health Policy Manag. 2013, 1, 193-199.

48. Machen, R.; Cuddihy, T.F.; Reaburn, P.; Higgins, H. Development of a Workplace Wellness Promotion Pilot Framework: A Case Study of the Blue Care Staff Wellness Program. Asia-Pacific J. Health Sport Phys. Educ. 2010, 1, 13-20.

49. Love, J. Five Reasons Corporate Wellness Is More Important Than Ever. Forbes, 12 August 2013. Available online: http://www.forbes.com/sites/theyec/2013/09/12/five-reasons-corporate-wellness-is -more-important-than-ever/ (accessed on 10 August 2014).

50. Nield, D. Employee Wellness Programs Now One of Fitbit's Fastest Growing Areas. Digital Trends, 19 April 2014. Available online: http:/www.digitaltrends.com/mobile/employee-wellnessprograms-now-one-fitbits-fastest-growing-areas/\#!bDRFJr (accessed on 10 August, 2014).

51. Olson, P.; Tilley, A. The Quantified Other: Nest And Fitbit Chase A Lucrative Side Business. Forbes, 17 April 2014. Available online: http://www.forbes.com/sites/parmyolson/2014/04/17/ the-quantified-other-nest-and-fitbit-chase-a-lucrative-side-business/ (accessed on 10 August 2014).

52. Henning, K.J. Overview of Syndromic Surveillance: What is Syndromic Surveillance? MMWR 2004, 53 (Suppl), 5-11.

53. Fowler, T.; Elliot, D.; Saunders, K.; Fearne, A. Using supermarket consumer data for public health: novel findings from Loyalty Card Data. Available online: http://em.hee.nhs.uk/wp- 
content/uploads/sites/476/2014/02/Using-Supermarket-Consumer-Data-for-Public-Health-TomFowler.pdf (accessed on 10 August 2014).

54. Pettypiece, S.; Robertson, J. Your Doctor Knows You're Killing Yourself: The Data Brokers Told Her. Bloomberg, 26 June 2014. Available online: http://www.bloomberg.com/news/2014-0626/hospitals-soon-see-donuts-to-cigarette-charges-for-health.html (accessed on 10 August 2014).

55. Haraway, D. Simians, Cyborgs, and Women: The Reinvention of Nature; Free Association: London, UK, 1991.

56. Lupton, D. The Digital Cyborg Assemblage: Haraway's Cyborg Theory and the New Digital Health Technologies. In The Handbook of Social Theory for the Sociology of Health and Medicine; Collyer, F., Ed.; Palgrave Macmillan: Houndmills, UK, 2013.

57. Caffentzis, G. The work/energy crisis and the apocalypse. Available online: http://ibcom.org/ library/workenergy-crisis-apocalypse-george-caffentzis (accessed on 9 March 2014).

58. Herschbach, L. Prosthetic reconstructions: Making the industry, re-making the body, modelling the nation. Hist. Workshop 1997, 44, 22-57.

59. Seltzer, M. Bodies and Machines; Routledge: London, UK, 1992.

60. Wark, M. Considerations on a Hacker Manifesto. In Digital Labor: The Internet as Playground and Factory; Scholz, T., Ed.; Routledge: London, UK, 2013; pp. 69-75.

61. Oprescu, F.; Jones, C.; Katsikitis, M. I PLAY AT WORK - ten principles for transforming work processes through gamification. Front. Psychol. 2014, 5, 1-5.

62. Smith, R. The Future of Work is Play: Global Shifts Suggest Rise in Productivity Games. In Proceedings of the Games Innovation Conference, 2011 IEEE International, Orange, CA, USA, 2-3 November 2011.

63. Ong, A. Neoliberalism as Exception: Mutations in Citizenship and Sovereignty; Duke University Press: Durham, NC, USA, 2006.

64. Aytes, A. Return of the Crowds: Mechanical Turk and Neoliberal States of Exception. In Digital Labor: The Internet as Playground and Factory; Scholz, T., Ed.; Routledge: London, UK, 2013; pp. 79-97.

65. Andrejevic, M. Estranged Free Labor. In Digital Labor: The Internet as Playground and Factory; Scholz, T., Ed.; Routledge: London, UK, 2013; pp. 149-164.

66. Ruckenstein, M. Visualized and Interacted Life: Personal Analytics and Engagements with Data Doubles. Societies 2014, 4, 68-84.

67. Wilson, H.J. Wearable Gadgets Transform How Companies Do Business. Available online: http://online.wsj.com/news/articles/SB10001424052702303796404579099203059125112 (accessed on 9 March 2014).

(C) 2014 by the author; licensee MDPI, Basel, Switzerland. This article is an open access article distributed under the terms and conditions of the Creative Commons Attribution license (http://creativecommons.org/licenses/by/3.0/). 